\title{
New Dynamic Analysis and System Identification of Biodiesel Production Process from Palm Oil
}

\author{
Ahmmed S. Ibrehem * and Hikmat S. Al-Salim \\ Chemical \& Petroleum Engineering Department, University of Sedaya, Kuala \\ Lumpur,50603, Malaysia
}

Received: 12nd November 2009; Revised: 20th Decmber 2009; Accepted: 27th December 2009

\begin{abstract}
In this study we present advanced mathematical model was used to capture the batch reactor characteristics of reacting compounds new parameters and new a prerequisite average slope analysis (PASA) method for the system dynamic behaviour under different operational conditions is a prerequisite to the good selection for these parameters. The model was applied to batch reactor for the production of bio-diesel from palm and kapok oils. Results of the model were compared with experimental data in terms of conversion of transesterification reaction for the production of bio-diesel under unsteady state. A good agreement was obtained between our model predictions and the experimental data. Both experimental and modeling results showed that the conversion of triglycerides to methyl ester was affected by the process conditions and by using PASA that could be achieved by making some deterministic tests either in real data plant or in the physical model that properly and adequately fits the actual process. The input-output relationships are studied using the open-loop dynamic response of the process, which can be determined from the process model by stepping different inputs and recording output responses. Starting from steady state conditions, each input is perturbed with certain magnitude that is enough to show the effect on the system dynamics. The transesterficition process with temperature of about $70{ }^{\circ} \mathrm{C}$, and methanol ratio to the triglyceride of about 5 times its stoichiometry and the $\mathrm{NAOH}$ catalyst of wt $0.4 \%$, appear to be acceptable process conditions. PASA shows methanol ratio to the triglyceride has big effect on the system. PASA method can be applied for different processes. (C) 2009 BCREC. All rights reserved.
\end{abstract}

Keywords: Mathematical model, System identification, Vegetable oil, Catalytic reactor, Dynamic study

\section{Introduction}

A new mathematical model (Ibrehem and AlSalim, 2009) was derived to describe production processes by the most active input variables inside batch reactor as shown in Figure (1). The model was applied to a process of production of bio-diesel from vegetable oils. Production of bio diesel from

* Corresponding Author.

E-mail address: ahmadsaadi1@yahoo.com (Ibrehem)

Tel: +061-0149360913, Fax: +061-98-9985241 vegetable oils received a lot of attention and may be one day will become one of the most important renewable energy sources for transport and household uses (Dunn, 2008). Both Malaysia and Indonesia have recently started developing bio-diesel derived from vegetable oils (Antaresti et.al., 2005) in large quantities using different sources for the oil 
(Franceschini and Macchietto, 2007). Production of bio diesel from vegetable oils received a lot of attention and may be one day will become one of the most important renewable energy sources for transport and household uses.

Both Malaysia and Indonesia have recently started developing bio-diesel derived from vegetable oils (Antaresti et.al., 2005) in large quantities using different sources for the oil. What makes bio diesel important is attributed to its chemical and physical properties which closely resemble those of diesel fuel. This has been documented by many authors (Clark et al., 1984; Mittelbach and Tritthart, 1988; Pakpahan, 2001; Legowo, 2001). The bio-diesel cetane number, energy content, viscosity and phase changes are similar to those of petroleum based diesel fuel, but is essentially sulfur free. Bio-diesel offers enhanced safety characteristics when compared to diesel fuel. It has a higher flash point and does not produce explosive air/fuel vapors. Generally bio-diesel fuel less toxic than petroleum fuel due to the absence of aromatics hydrocarbons. Bio-diesel is made by transesterification of triglyceride found in natural oils with methanol in the presence of a catalyst. Transesterification of a vegetable oil was conducted as early as 1853 by scientists E. Duffy and J. Patrick, many years before the first diesel engine became functional. Rudolf Diesel's prime model, a single $10 \mathrm{ft}(3 \mathrm{~m})$ iron cylinder with a flywheel at its base, ran on its own power for the first time in Augsburg, Germany, on August 10, 1893.

In remembrance of this event, August 10 has been declared "International Biodiesel Day.The French Otto Company (at the request of the French government) demonstrated a Diesel engine running on peanut oil at the World Fair in Paris, France in 1900, where it received the Grand Prix (highest prize).

This engine stood as an example of Diesel's vision because it was powered by peanut oil a biofuel, though not biodiesel, since it was not transesterified. He believed that the utilization of biomass fuel was the real future of his engine. In a 1912 speech Diesel said, "the use of vegetable oils for engine fuels may seem insignificant today but such oils may become, in the course of time, as important as petroleum and the coal-tar products of the present time."

During the 1920s, diesel engine manufacturers altered their engines to utilize the lower viscosity of petrodiesel (a fossil fuel), rather than vegetable oil (a biomass fuel). The petroleum industries were able to make inroads in fuel markets because their fuel was much cheaper to pro- duce than the biomass alternatives. The result, for many years, was a near elimination of the biomass fuel production infrastructure. Only recently have environmental impact concerns and a decreasing price differential made biomass fuels such as biodiesel a growing alternative.

Despite the widespread use of fossil petroleumderived diesel fuels, interest in vegetable oils as fuels for internal combustion engines was reported in several countries during the 1920s and 1930s and later during World War II. Belgium, France, Italy, the United Kingdom, Portugal, Germany, Brazil, Argentina, Japan and China were reported to have tested and used vegetable oils as diesel fuels during this time. Some operational problems were reported due to the high viscosity of vegetable oils compared to petroleum diesel fuel, which results in poor atomization of the fuel in the fuel spray and often leads to deposits and coking of the injectors, combustion chamber and valves. Attempts to overcome these problems included heating of the vegetable oil, blending it with petroleumderived diesel fuel or ethanol, pyrolysis and cracking of the oils.

On August 31, 1937, G. Chavanne of the University of Brussels (Belgium) was granted a patent for a "Procedure for the transformation of vegetable oils for their uses as fuels" (fr. "Procédé de Transformation d'Huiles Végétales en Vue de Leur Utilisation comme Carburants") Belgian Patent 422,877. This patent described the alcoholysis (often referred to as transesterification) of vegetable oils using ethanol (and mentions methanol) in order to separate the fatty acids from the glycerol by replacing the glycerol with short linear alcohols. This appears to be the first account of the production of what is known as "biodiesel" today.

More recently, in 1977, Brazilian scientist Expedito Parente invented and submitted for patent, the first industrial process for the production of biodiesel. This process is classified as biodiesel by international norms, conferring a "standardized identity and quality. No other proposed biofuel has been validated by the motor industry." Currently, Parente's company Tecbio is working with Boeing and NASA to certify bioquerosene (bio-kerosene), another product produced and patented by the Brazilian scientist.

Research into the use of transesterified sunflower oil, and refining it to diesel fuel standards, was initiated in South Africa in 1979. By 1983, the process for producing fuel-quality, engine-tested biodiesel was completed and published internationally. An Austrian company, Gaskoks, obtained the technology from the South African Agricultural 
Engineers; the company erected the first biodiesel pilot plant in November 1987, and the first industrial-scale plant in April 1989 (with a capacity of 30,000 tons of rapeseed per annum).

Throughout the 1990s, plants were opened in many European countries, including the Czech Republic, Germany and Sweden. France launched local production of biodiesel fuel (referred to as diester) from rapeseed oil, which is mixed into regular diesel fuel at a level of $5 \%$, and into the diesel fuel used by some captive fleets (e.g. public transportation) at a level of $30 \%$. Renault, Peugeot and other manufacturers have certified truck engines for use with up to that level of partial biodiesel; experiments with 50\% biodiesel are underway. During the same period, nations in other parts of the world also saw local production of biodiesel starting up: by 1998, the Austrian Biofuels Institute had identified 21 countries with commercial biodiesel projects. $100 \%$ Biodiesel is now available at many normal service stations across Europe.

In September 2005 Minnesota became the first U.S. state to mandate that all diesel fuel sold in the state contain part biodiesel, requiring a content of at least $2 \%$ biodiesel. In 2008, ASTM published new Biodiesel Blend Specifications Standards. In 2005, Franceschini and Macchietto derived modelbased experiment design techniques for bio-diesel process based on experimental data only, while Dunn (2008) derived a mathematical model to calculate the temperature effects on the system. The two models did not include the effect of catalysts and concentration of reactants unlike our model which takes into it all variables such as temperature, concentration of reactants, and catalyst. New mathematical model calculates the effects of concentrations of triglycerides, methanol, catalyst weight percent and temperature of reaction on the percent of conversion.

Based on the Antaresti et.al. (2005) work experimental basics of reactor design and the results of experiments on the various conditions. Design a complete mathematical model of the system by using computer software such as MATLAB, the system is simulated and results compared to the experimental results and give acceptable results between new model predictions and the experimental data.

In this paper, we address the following question: what types of input signals are sufficient to completely identify the input/output behavior of a system? In other words, we look for classes $\mathrm{x}$ of inputs with the property that, if a system is stimulated with the inputs from the set $\mathrm{x}$ and the corresponding time record of outputs is recorded, then, on the basis of the collected information on inputs and outputs it is possible at least theoretically, with no regard to computational effort, and in the absence of noise to obtain a system output which is equivalent to y. By "equivalent" we mean that the estimated system will be completely indistinguishable from the true system in its input/output behavior.

\section{Modified Mathematical Model}

A mathematical model was applied to Antaresti. et.al experimental work which deals with the relationship between rate coefficient $(\mathrm{k})$ of the reaction with weight percent of $\mathrm{NaOH}$ as a catalyst (cat). A numerical polynomial relationship depending on experimental results was developed in our model by using version seven MATLAB software to give high accuracy (more than 99\%) in calculating the rate coefficient $(\mathrm{k})$ of the reaction which makes it suitable to use in calculating the rate of reaction $\left(\mathrm{r}_{\mathrm{A}}\right)$, mass balance $\left(\mathrm{C}_{\mathrm{A}}\right)$ and $\left(\mathrm{C}_{\mathrm{B}}\right)$ for the reactor, as well as energy balance ( $\mathrm{T}_{\text {react }}$ ) for reactor and the jacket $\left(\mathrm{T}_{\text {jacket}}\right)$ as shown in Figure (1). The estimation of the reactor model parameters are given in Table (1). The relationship between rate coefficients of the reaction with weight percent of $\mathrm{NaOH}$ as a catalyst is given by:

$$
\begin{aligned}
k= & 4.1562 \times 10^{-16} \text { cat }^{3}-0.011905 \text { cat }^{2} \\
& +0.03952 \text { cat }+0.0065714
\end{aligned}
$$

Reactor mole balances for triglycerides (A) in volume (v):

Mole in - Mole out + Generation $=$ Rate of accumulation of mass

$$
\begin{aligned}
& 0-0-r_{A} v=v \frac{d C_{A}}{d t} \\
& \frac{d C_{A}}{d t}=-k C_{A} C_{B}
\end{aligned}
$$

Reactor mole balance for methanol (B) in volume (v):

Mole in - Mole out + Generation $=$ Rate of accumulation of mass

$$
\begin{aligned}
& 0-0-r_{A} v=v \frac{d C_{B}}{d t} \\
& \frac{d C_{B}}{d t}=-k C_{A} C_{B}
\end{aligned}
$$


Reactor Energy Balance:

Energy in - Energy out + Energy generated - Energy observed $=$ Rate of accumulation

$$
\begin{gathered}
0-0+U A\left(T_{\text {jacket }}-T_{\text {react }}\right)+r_{A} V(\Delta H)=\rho V C_{p} \frac{d T_{\text {react }}}{d t} \\
U A\left(T_{\text {jacket }}-T_{\text {react }}\right)-k C_{A} C_{B} V(\Delta H)=\frac{d T}{d t} \\
\frac{d T}{d t}=\frac{\left[U A\left(T_{\text {jacket }}-T_{\text {react }}\right)-k C_{A} C_{B} V(\Delta H)\right]}{\rho V C_{p}}
\end{gathered}
$$

Jacket Energy Balance:

Energy in - Energy out + Energy generated $=$ Rate of accumulation

\section{Results and calculations}

Figure (2) shows the results of our model along with (Antaresti et.al., 2005) results. The comparison between the results of the model presented in this work with the actual experimental data (Antaresti et.al., 2005) is made and gave us high accuracy as shown in Figure (2) for the system triglycerides conversion for different catalyst weight percent. Weight percentage of catalyst has big effects on triglycerides conversion because the

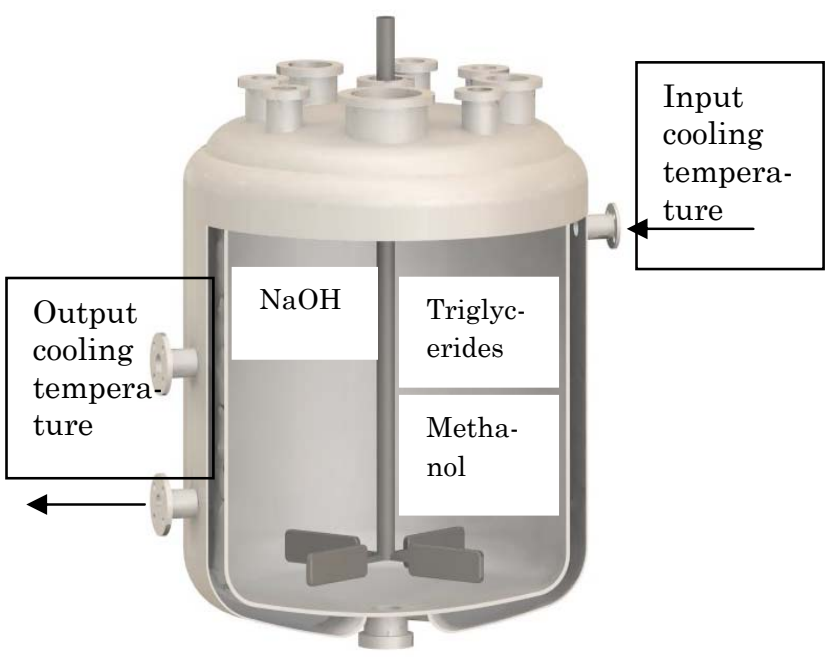

Figure 1. A diagram of batch reactor for bio-diesel process

\begin{tabular}{|c|c|}
\hline Fuel properties & Bio diesel \\
\hline Lower heating value Btu/gal & 118,170 \\
\hline Kinematic viscosity @40 C & $4.0-6.0$ \\
\hline Specific gravity kg/l@60 •F & 0.88 \\
\hline Density,b/gal @15 C & 7.328 \\
\hline Water and Sediment, vol\% & $0.05 \max$ \\
\hline Carbon, wt $\%$ & 77 \\
\hline Hydrogen, wt\% & 12 \\
\hline Oxygen, wt $\%$ & 11 \\
\hline Sulfur, wt\% & 0.0 to 0.0024 \\
\hline Boiling point, ${ }^{\circ} \mathrm{C}$ & 315 to 350 \\
\hline Flash point, ${ }^{\circ} \mathrm{C}$ & 100 to 170 \\
\hline Cold point, ${ }^{\circ} \mathrm{C}$ & -3 to 12 \\
\hline Pour point, ${ }^{\circ} \mathrm{C}$ & -15 to 10 \\
\hline Cetane number & $48-65$ \\
\hline Initial temperature, ${ }^{\circ} \mathrm{C}$ & 25 \\
\hline Initial pressure, atm & 1 \\
\hline Catalyst,wt\% & 0.1 to 0.5 \\
\hline $\begin{array}{l}\text { MET/ TRI } \\
\text { Initial temperature of water } \\
\text { jacket, }{ }^{\circ} \mathrm{C}\end{array}$ & $\begin{array}{c}1 \text { to } 5 \\
90\end{array}$ \\
\hline $\begin{array}{l}\text { Over all heat transfer coeffi- } \\
\text { cient, } \mathrm{U}\left[\mathrm{W} / \mathrm{m}^{2} . \mathrm{K}\right]\end{array}$ & 851 \\
\hline Coolant densities, pc $\left[\mathrm{kg} / \mathrm{m}^{3}\right]$ & 1000 \\
\hline $\begin{array}{l}\text { Process heat capacities Cpo and } \\
\mathrm{Cp}[\mathrm{J} / \mathrm{kg} . \mathrm{K}]\end{array}$ & 3574 \\
\hline $\begin{array}{l}\text { Coolant heat capacities Cpo } \\
{[\mathrm{J} / \mathrm{kg} \cdot \mathrm{K}]}\end{array}$ & 4183 \\
\hline $\mathrm{Fc}\left[\mathrm{m}^{3} / \mathrm{s}\right]$ & 0.12 \\
\hline Area of cooling jacket, $\mathrm{m}^{2}$ & 0.25 \\
\hline Volume of cooling jacket, $\mathrm{Vc}, \mathrm{m}^{3}$ & 0.3 \\
\hline Tank base radius $(\mathrm{R})[\mathrm{m}]$ & 0.5 \\
\hline Tank height $(\mathrm{H})[\mathrm{m}]$ & 1.5 \\
\hline
\end{tabular}

Table 1. Physical constants and operating parameters for the mathematical model system 
weight percentage of catalyst effects on rate constant of reaction that leads to increase the conversion as shown in Figure (2) when the catalyst weight percentage increase from $0.1 \%$ to $0.2 \%$ the conversion increase more than $8 \%$. So, if the weight of catalyst increases to $5 \%$ the conversion will increase more than $40 \%$ that give us a very good idea about the effects of weight of catalyst in the system. Meanwhile, Figure (3) shows the effects different weight ratio of methanol (MET) to triglycerides (TRI) on triglycerides conversion that give us a very good idea about the accuracy of this model and big effects of increasing ratio of MET/ TRI in the system. The conversion will be increased more than $45 \%$ if the ratio increases from 1 to 5 as shown in Figure (3). While Figures (4) and (5) show the effects different concentration step changes of TRI on the temperature of reaction with the time and different weight percent of catalyst step change on the concentration of TRI with the time respectively. Once again there is a good agreement between the new model and the actual experimental data.

\section{Dynamic Analysis and Identification for Mathematical Model}

System identification involves building a dynamical model from an input/output data and without use of any laws concerning the fundamental nature and properties of the nonlinear system. The batch reactor process involves many variables, which contribute to its operation, and this makes it a Single-Input Single-Output (SISO) process. These variables are classified as follows:

Input or manipulated variables (MVs) are chosen from those variables that have direct effect on the process performance, and practically easy to actuate. In our case, these are: percent of $\mathrm{NaOH}$ as a catalyst $(\mathrm{Qc})$ and ratio of $\mathrm{MET} / \mathrm{TRI}$ stoichiome-

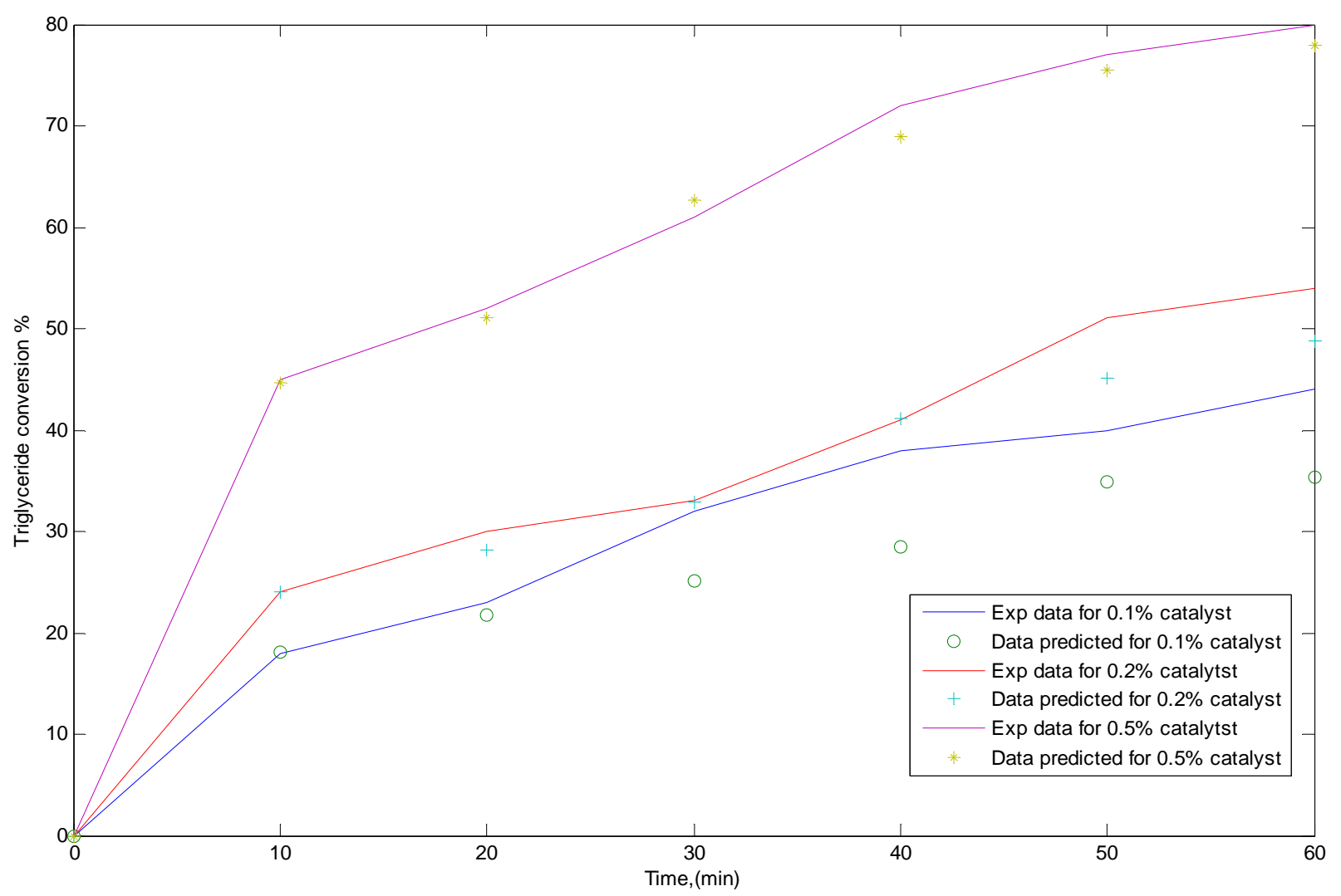

Figure 2. Effect of time on the transesterification process of vegetable oil for different percentage of weight catal 
try. The controlled variables (CVs) are selected from the process outlet streams that are usually of foremost importance such as the triglycerides conversion (TRI). A schematic diagram representing the previously mentioned variables is shown in Figure (6).

So, the identification steps can be defined for PASA as follows;

1. First step is to make actual calculations for the system from nominal conditions $x n, i$ to calculate yn,i.

2 . Second step repeat step one with $+33 \%$ perturbed parameter input vector $\left(1.33 \times \mathrm{x}_{\mathrm{n}, \mathrm{i}}\right)$ to produce the $+33 \%$ perturbed output yi matrix.

3. Third subtract each element from matrix in first step from the corresponding element in matrix in second step and divided the difference by $\mathrm{y}_{\mathrm{n}, \mathrm{i}} \cdot\left(\mathrm{y}_{\mathrm{i}}-\mathrm{y}_{\mathrm{n}, \mathrm{i}}\right) / \mathrm{y}_{\mathrm{n}, \mathrm{i}}$.

4. Fourth step similarly calculate the change in parameters $\left(\mathrm{x}_{\mathrm{i}}-\mathrm{x}_{\mathrm{n}, \mathrm{i}}\right) / \mathrm{x}_{\mathrm{i}}$.
5. Fifth step divided each element in third step by fourth step to produce the sensitivity matrix k. Depends completely on scale matrix without using any a proper factor.

6. Sixth step calculate $\mathrm{k}$ matrix for negative direction which mean calculate $\mathrm{k}+33 \%$ and $\mathrm{k}-33 \%$ so as, we can check the effect of each parameters on output as seen in Table (2) .

Then find average slope to find average angle $(\theta)$ that is represented overall effect of each parameters on the measured output ( $\theta_{1}$ represents the effects of MET/TRI and $\theta_{2}$ represents the effects of catalyst on the system as shown in Figure (7).

From parameters average slope analysis we can see a preliminary partitioning of estimating into different groups depend on slope angle $(\theta)$ of kaverage and these groups can be specified as follows;

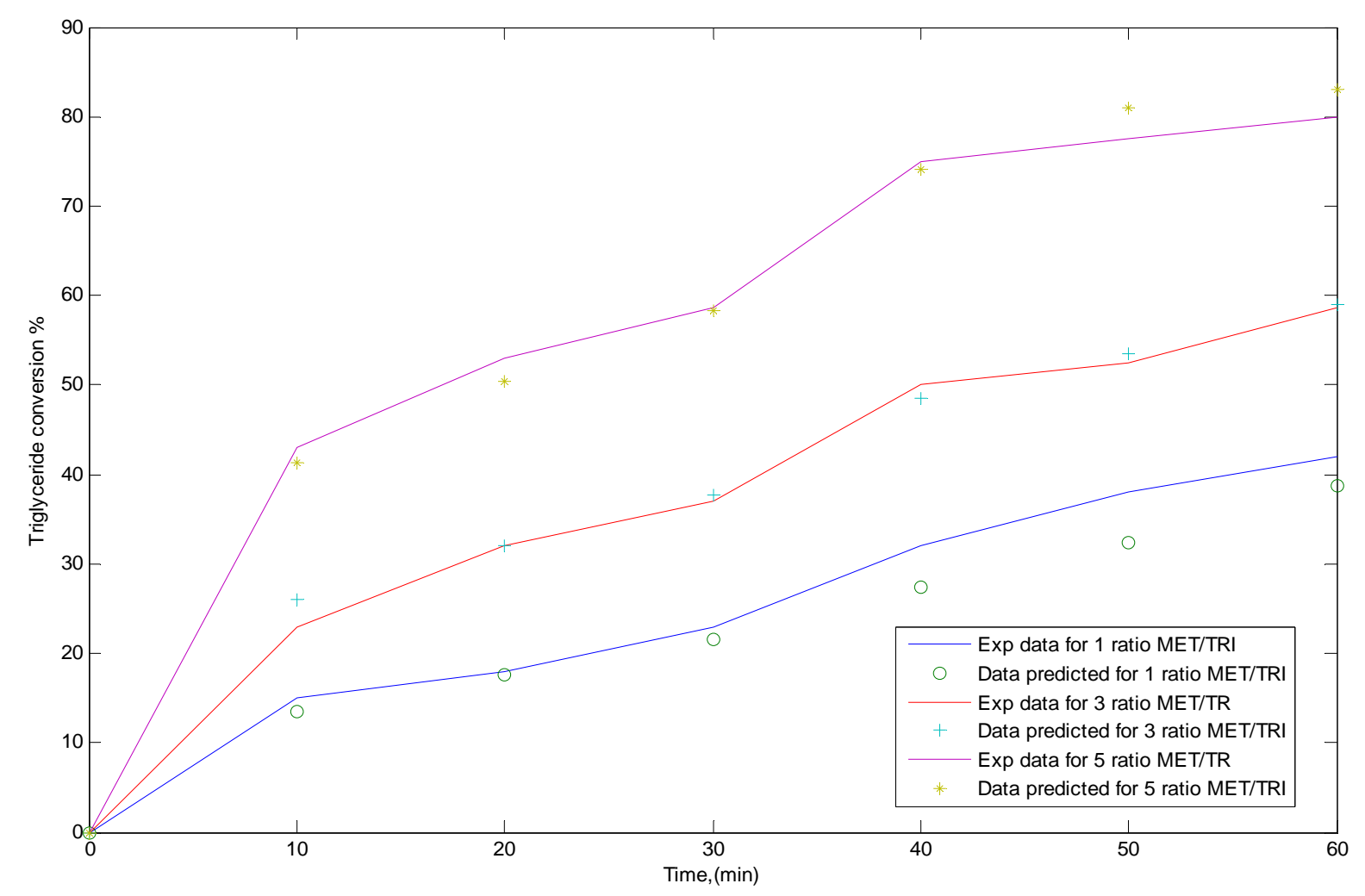

Figure 3. Effect of time on the transesterification process of vegetable oil for different ratio of MET/ TRI stoichiometry 


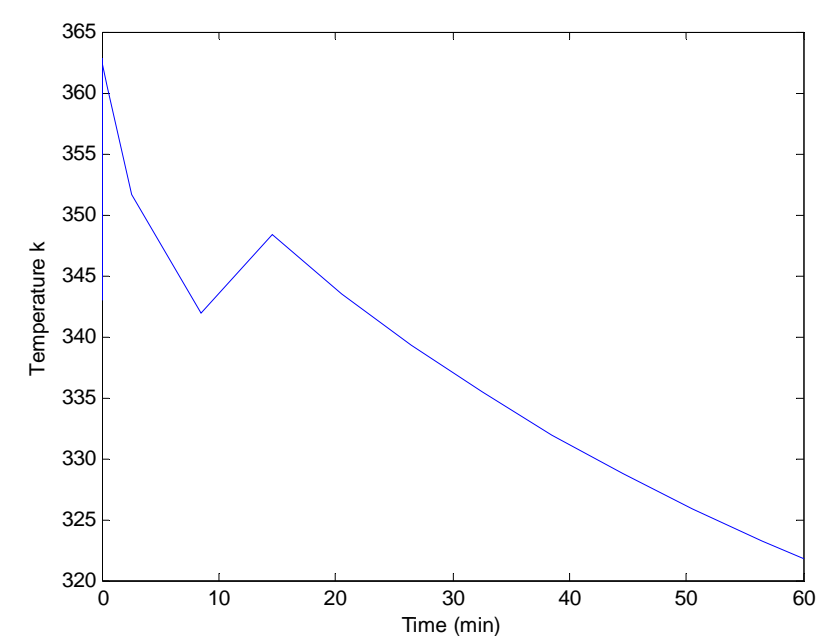

Figure 4. Effect of concentration step change of TRI on the temperature of reaction with the time (concentration of TRI $=2 \mathrm{kmol} / \mathrm{m} 3$ from time $=0$ min until $14 \mathrm{~min}$ then concentration of TRI $=0.5$ $\mathrm{kmol} / \mathrm{m} 3$ at time $14.5 \mathrm{~min})$.

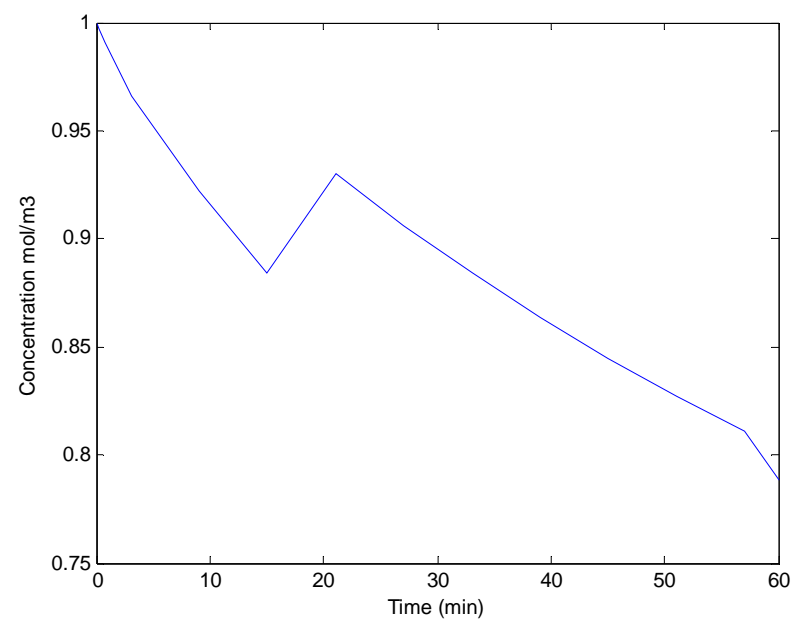

Figure 5. Effect of weight percent of catalyst step change on the concentration of TRI with the time (weight percent of catalyst $=0.5$ from time $=0$ min until $15 \mathrm{~min}$ then weight percent of catalyst $=0.1$ at time $14 \mathrm{~min}$ ).

\section{Manipulated \\ Variables}

\section{Out put}

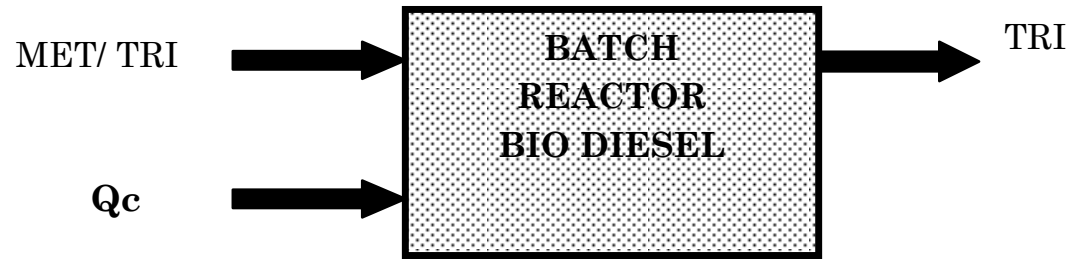

Figure 6. Representation of variables in bio diesel system as a MISO system

Table 2. Calculate the percent difference for output profile

\begin{tabular}{llllll}
\hline MET/ TRI & $\begin{array}{l}\text { TRI differ- } \\
\text { ence } \%\end{array}$ & $\mathrm{~K}_{\text {average }}$ & Qc weight \% & $\begin{array}{l}\text { TRI difference } \\
\%\end{array}$ & $\mathrm{~K}_{\text {average }}$ \\
\hline 2 & 54 & 0.615 & 0.2 & 58 & 0.237 \\
3 & 68 & 0.396 & 0.3 & 63 & 0.57 \\
4 & 77 & & 0.4 & 75 & 0.4035 \\
\hline Average $\%$ & & 0.5055 & & & 21.90 \\
$\theta$ Average & & $26.81^{\circ}$ & & & \\
\hline
\end{tabular}




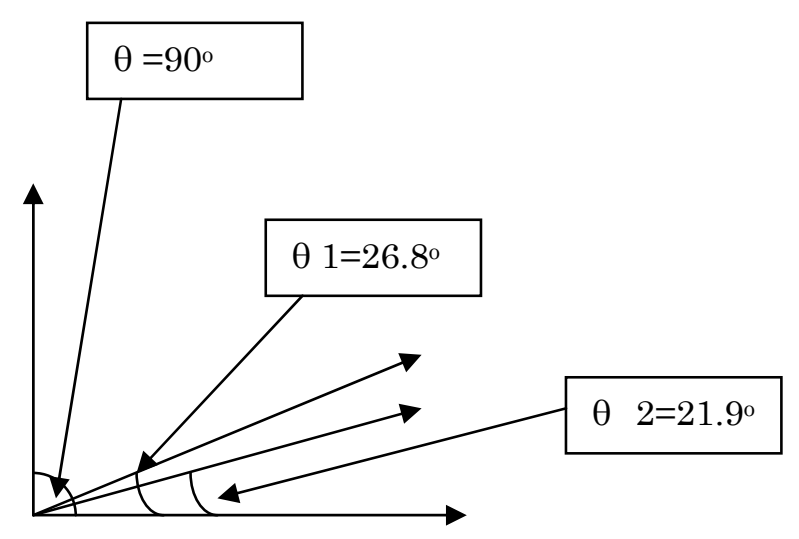

Figure 7. Represents the slope average angle slope

- $\quad(\theta) \geq 20^{\circ}$ : Large effects on the system.

- $20^{\circ}>(\theta)>15^{\circ}$ : Middle effects on the system.

- $15^{\circ} \geq(\theta) \geq 10^{\circ}$ : Weak effects on the system.

- $10^{\circ}<(\theta)$ : Can not be established.

\section{Conclusion}

New identification and analysis for new dynamic model for bio diesel was developed in this work and a new dynamic bio-diesel model was established in this work by using three differential equations mass balance equation for reactor system, heat balance equation for reactor system and heat balance for cooling jacket. New technique is used in this model to calculate rate constant by depending into account experiments results between the catalyst weight percent and rate constant to produce third order polygon equation. This model takes into account the presence of catalyst weight percent, ratio of methanol to triglycerides, temperature of reaction, and temperature supply for reactor on conversion percent of triglycerides which depend on these parameters. The model presented in this work was compared with experimental data at unsteady state for conversion percentage of triglycerides of the bio-diesel batch reactor process. From its observed accuracy, we can conveniently use this model as a predictive tool to study the effects of operating, and kinetic parameters on the reactor performance. The results between the new model and the experimental results gave a good indication about the behavior of the present model which is very close to experimental data.

This model takes into account the presence of particles participating in the reaction with TRI conversion which depend on the ratio MET/TRI and catalyst weight percentage. The comparison results between these two inputs gave good indication about the behavior of the present model the identification results gave good indication for effects of the ratio MET/TRI and catalyst weight percentage on the system. The ratio MET/TRI has more a great affects on the system compared to the catalyst weight percentage as see in Table (2) and Figure (7). This kind of identification and analysis method can be used to any system to identify which is the best input variables that effects on any system

\section{REFERENCES}

[1] Ahmmed S Ibrehem, and Hikmat S Al-Salim. Advanced Mathematical Model to Describe the Production of Bio-diesel Process, Bulletin of Chemical Reaction Engineeringt \& Catalysis, Article Inpress, 2009

[2] Clark,S.,J.,Wagner, L., Schrock, M.D., and Pinnaar,P.G.1984.Methyl and ethyl esters as renewable fules for diesel engines. J. Amer. Oil Chem. Soc.,61,1632-1638.

[3] Legowo, E.2001,Experience in Palm Biodiesel uses for Transportation, Proceedings of the International Biodiesel Workshop, Medan, Indonesia.

[4] Mittelbach and Tritthart, P.1988.Diesel fuel derived from vegetable oils, III Emission test using methyl esters of used frying oils $J$. Amer. Oil Chem. Soc., 65, 1185-1187.

[5] Muniyappa, P.R.,Brammer, S.C., and Noureddini,H.1996.Improved conversion of plant oils and animal fats into biodiesel and co-product, Biodiesel Technology, 56,19-24.

[6] Pakpahan,A.2001. Palm Biodiesel: Its potency, technology, business prospect and environmental implication in Indonesian, Proceeding of the International Biodiesel Wworkshop, medan, Indonesia.

[7] Antaresti. et.al., 2005. The Biodiesel Production Process from Vegetable Oil, Dev. Chem. Eng. Mineral Process. 13(5/6), pp.687692,2005 .

[8] Dunn, R.O. 2008. Effect of temperature on oil stability index (OSI) of biodiesel. Energy and Fuels. 22:657-662.

[9] Gaia Franceschini and Sandro Macchietto, Validation of a Model for a Biodiesel Production Process through Model-Based Experiment Design for Parameter Precision, Computers and Chemical Engineering, 24, 12611267.

[10] SAE Technical Paper series no. 831356. SAE International Off Highway Meeting, Milwaukee, Wisconsin, USA, 1983 